\title{
AC 2010-1293: ENERGY HARVESTING INVESTIGATIONS BY UNDERGRADUATE ENGINEERING TECHNOLOGY STUDENTS
}

\section{Dale Litwhiler, Pennsylvania State University, Berks}

Dale H. Litwhiler is an Associate Professor at Penn State, Berks Campus in Reading, PA. He received his B.S. from Penn State University (1984), his M.S. from Syracuse University (1989) and his Ph.D. from Lehigh University (2000) all in electrical engineering. Prior to beginning his academic career in 2002, he worked with IBM Federal Systems and Lockheed Martin Commercial Space Systems as a hardware and software design engineer.

\section{Thomas Gavigan, Penn State Berks}

Thomas H. Gavigan is an Assistant Professor at Penn State, Berks Campus in Reading, PA. He received his B.S. in Mechanical Engineering from Drexel University in 1970 and his M.S. in Engineering Mechanics from Penn State in 1977. Mr. Gavigan teaches in the areas of Engineering Mechanics and Engineering Design.

\section{Brittany Farrell, Penn State Berks}

Brittany Farrell received her Associate's Degree in Mechanical Engineering Technology from Penn State Hazleton in 2008. In May 2010 she will receive her Bachelor's Degree in Electro-Mechanical Engineering Technology from Penn State Berks. Following graduation, Brittany will be pursuing a career in alternative energy. 


\title{
Energy Harvesting Investigations by Undergraduate Engineering Technology Students
}

\begin{abstract}
Energy harvesting is a very popular topic in current literature. However the concept of capturing small quantities of waste energy to power useful electrical devices is not new. The "selfwinding" wristwatch, which is powered by the motion of the wearer, was originally available decades ago, but public awareness of energy conservation and sustainability has brought new attention to this type of energy capture and use. Many energy harvesting systems are designed to capture mechanical energy, such as vibration, and convert it to electrical energy. The problem of converting small amounts of mechanical energy into electrical energy is well suited to investigation by undergraduate engineering technology students. The concepts learned in introductory courses are sufficient to allow the students to think of novel sources of mechanical energy and clever methods of capturing it. The apparatus required to make reasonably accurate measurements is quite simple and is easily constructed by the students in an engineering technology laboratory. Students are often familiar with some of the consumer devices available that convert human-generated energy into electrical energy such as hand-cranked and handshaken flashlights. Therefore, as a foray into the area of energy harvesting, commercially available devices are purchased and reverse-engineered by the students. The students disassemble and identify the key mechanical, electrical, and energy conversion components of the flashlights. The mechanical energy storage components are carefully measured and weighed. For rotating systems, the mass moment of inertia is calculated from the physical measurements. The students then reassemble the devices and conduct performance tests to determine the energy conversion efficiency of each system. Armed with the information gained from these investigations, students with more academic experience can perform more detailed analysis, performance measurements, and comparisons with systems employing different energy conversion devices. By using human power, the students get a real feel for the magnitude of a Watt and the importance of energy efficiency in energy harvesting applications. The results obtained from the testing and analysis performed by all the students is very useful in further development of custom energy harvesting device research. This paper presents the devices, apparatus, and methods used in the investigations as well as the results and conclusions as determined by the students involved.
\end{abstract}

\section{Motivation / Introduction}

In an effort to engage undergraduate engineering technology students in meaningful investigations, teams of first-year students were paired with engineering research faculty of various disciplines. The students were to be exposed to topics that challenged their neophytic 
understanding of pertinent engineering principles. The students had access to facilities and equipment not usually available in their first year. In some cases, as with that presented here, the students also benefited from work being performed by more senior student researchers. Ideas put forth by team members were evaluated and tried in near-real-time to determine their merit and effectiveness. Thus a "sandbox" environment was created.

The team investigation presented in this paper involved energy harvesting techniques. Previous work in this area has been presented. ${ }^{1}$ In the work presented here, the students investigated the efficiency of human-powered flashlight devices. These devices are becoming quite popular and are available from many sources. A myriad of device architectures is also available. After some internet research, the students decided to investigate two types of human-powered flashlights: One style employs a hand reciprocating (shaking) motion to drive the generator while the other uses a hand cranking motion. Figure 1 shows a photograph of each flashlight.
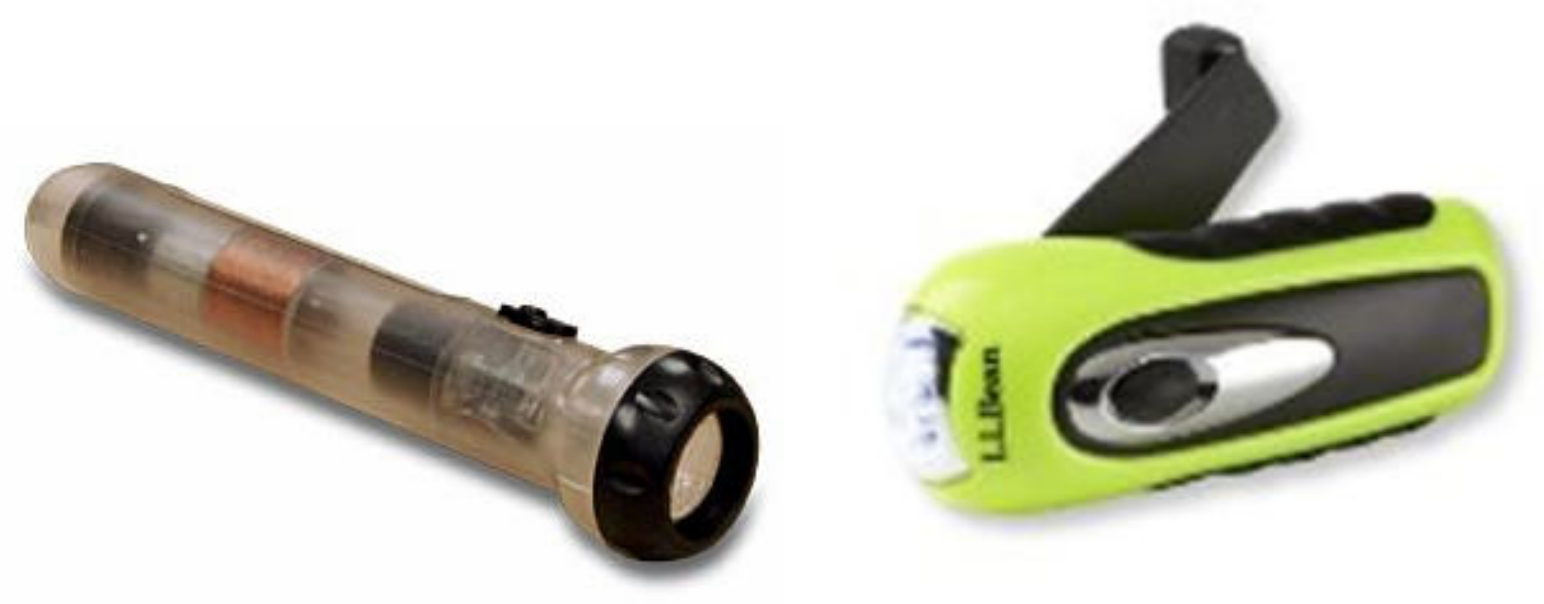

Figure 1. Shaker (left) and hand-crank flashlights.

Each of the flashlights contained a rechargeable battery that was charged via the human mechanical input energy. Both flashlights also used white light-emitting diodes as their illumination device. The electrical generation mechanisms, however, were vastly different.

A few units of each type of flashlight were purchased. One unit was for disassembly with no intentions of it ever being returned to its original state. The essential parts of the disassembled units were, however, still functional. In this way, the efficiency of the key system elements could be determined.

In parallel with the work being performed by the first-year students, a similar but separate independent investigation was being performed by a fourth-year engineering technology student. This investigation involved the conversion of mechanical energy stored in a spinning flywheel to electrical energy stored on a capacitor. The work on this project also started by disassembling a 
human-powered flashlight. In this case, the flashlight was powered by squeezing the handle of the device in a pumping action. Figure 2 shows a photograph of the hand-squeezed flashlight.

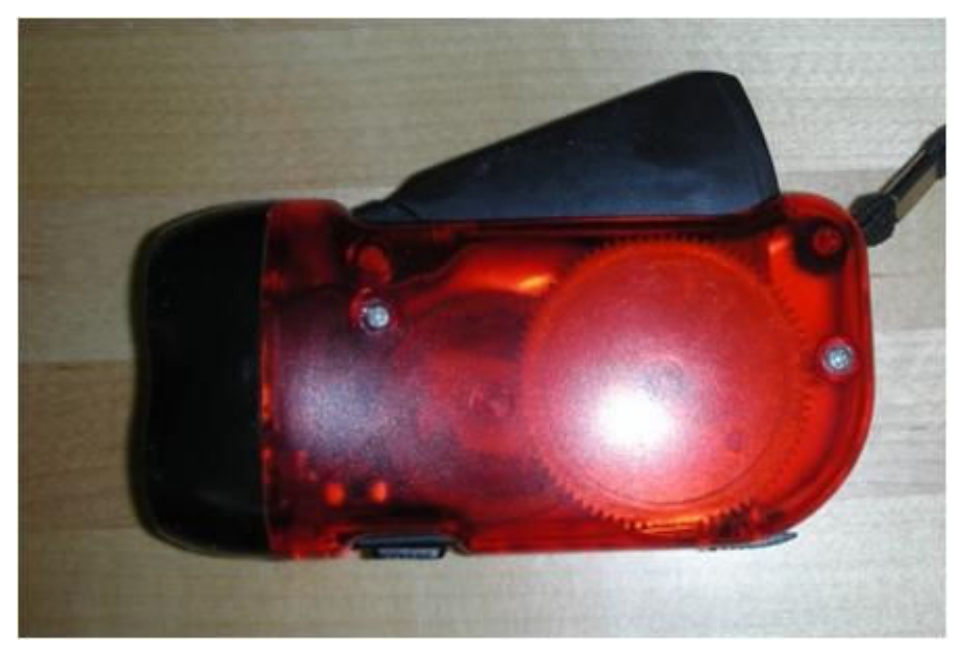

Figure 2. Hand-squeezed flashlight

The hand-squeezed flashlight was reverse-engineered to see what kind of mechanisms were used to convert the squeezing action to electrical energy. This type of conversion is similar to that needed in a faculty research project in which the student was involved. The student's work then turned to analyzing the energy contained in spinning flywheels and ways of converting it to electrical energy.

\section{Disassembly and Testing}

The careful disassembly of the flashlights allowed the students to engage in some "deconstructive learning." The team was instructed to carefully observe exactly how the flashlights were constructed before beginning to take them apart. They were also reminded that the individual pieces of the system must still be functional. With this in mind, the flashlights were sawed, unglued, unscrewed, pried and pulled apart. The internal circuit boards containing the battery, switches, rectifiers (if applicable), and LEDs were disconnected from the generator section. The electrical generator could then be tested alone.

\section{Shaker Flashlight}

The reciprocating (shaker) flashlight uses a very simple electrical generator consisting of a coil of wire through which a cylindrical magnet is free to slide. As the flashlight housing is shaken back and forth in the longitudinal direction, the magnet reciprocates through the coil thus inducing an alternating voltage. Figure 3 shows a photograph of the shaker flashlight coil and magnet. 


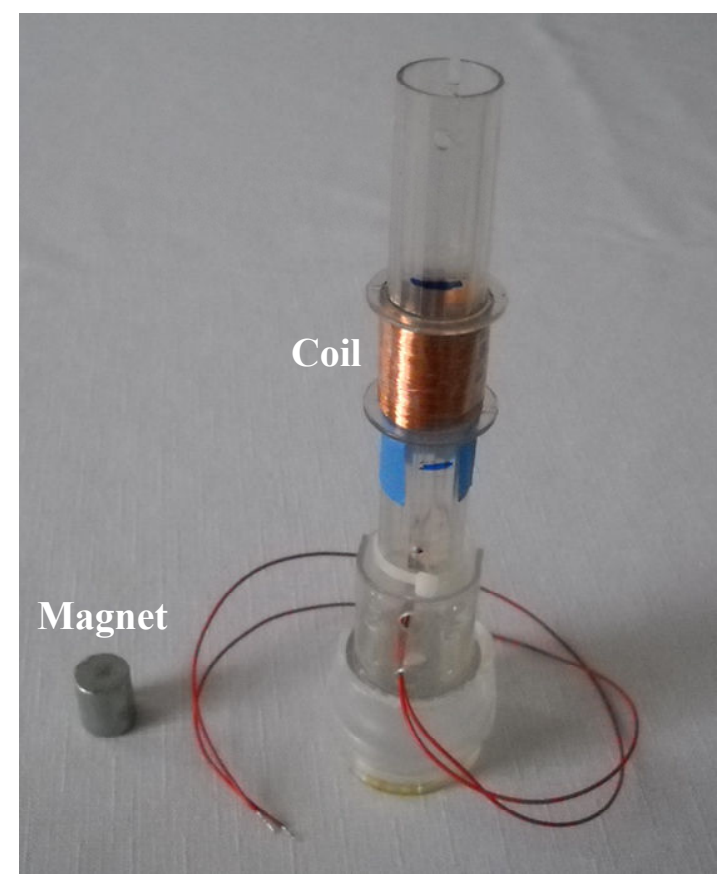

Figure 3. Shaker flashlight coil assembly and magnet

The magnet-coil generator system converts the mechanical energy of the moving magnet into electrical energy at the coil terminals. Thus, to evaluate the system efficiency, these two energies must be determined.

Brainstorming by the team produced the following method for determining the mechanical input energy:

1. Weigh the magnet and calculate its mass for use in the equations of motion.

2. Drop the magnet from a known height above the coil and calculate its speed and hence its kinetic energy in the coil using the equations of motion.

Just weighing the magnet proved to be problematic. When the cylindrically shaped magnet was placed on the scale, the indicated mass depended upon the magnet's orientation. Further investigation by the team found that the magnet's own magnetic field was interfering with the scale mechanism. Experimentation determined that if the magnet was held a few centimeters above the scale tray, the magnetic field disturbance was negligible. Therefore, the magnet was placed on a plastic box to hold it above the tray. The mass of the plastic box was then subtracted from the total indicated mass.

The flashlight coil axis was oriented vertically and the ends of the coil wires were connected to a digital oscilloscope. The magnet was dropped from rest starting with its bottom edge at the top of the cylinder as shown in Figure 4 (left). After a few trial drops of the magnet, the team 
observed the waveform shown in Figure 4 (right). Although the students were very confident in their equations of motion calculations, they were persuaded to consider using some of the information provided by the coil voltage waveform to determine the speed of the magnet.
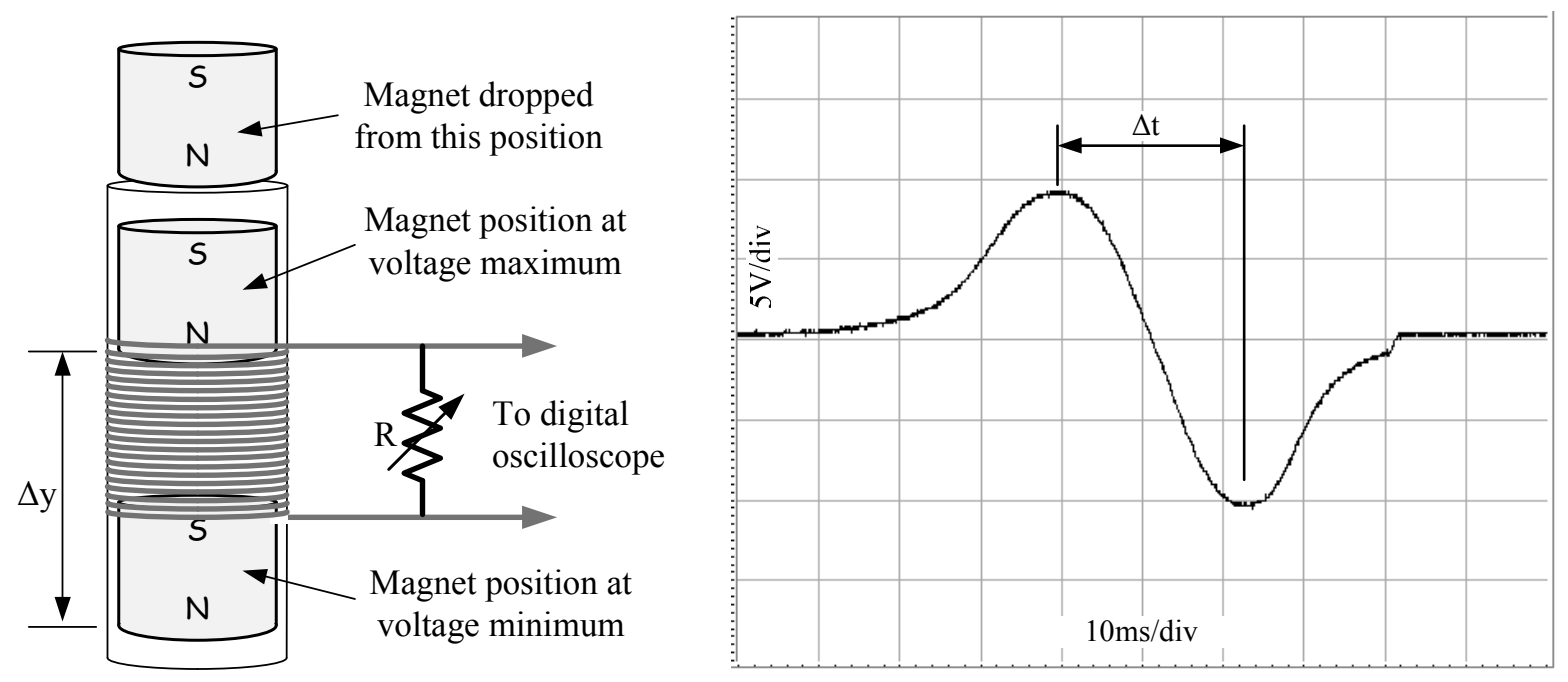

Figure 4. Shaker flashlight generator test setup and resulting waveform

The students studied the voltage waveform and, with a little help, concluded that the peak and valley must occur when the magnet is at specific locations within the coil. If these locations could be determined, then the time for the magnet to move between them could be read directly from the voltage plot. Therefore, the average speed of the magnet in the coil could also be measured, rather than calculated using the equations of motion.

By placing wooden obstructions in the cylinder to stop the falling magnet at any position, the team was able to accurately locate the points at which the voltage maximum and minimum occurred. The spacing between these locations is $\Delta y$ as shown in Figure 4 . On the voltage waveform, the time between the maximum and minimum is $\Delta \mathrm{t}$ also shown in Figure 4. Finally, the magnet velocity in the coil and the mechanical input energy could be calculated:

$$
\begin{aligned}
v & =\frac{\Delta y}{\Delta t} \\
W_{m} & =\frac{1}{2} m v^{2}
\end{aligned}
$$

The magnet mass was measured to be $22 \mathrm{~g}$. The distance between the magnet positions producing the voltage max and min, $\Delta \mathrm{y}$, was measured to be $26 \mathrm{~mm}$.

To determine the electrical output energy of the magnet-coil system, the coil output was loaded with various values of resistance while the voltage waveform was recorded with a digital 
oscilloscope as before. The voltage waveform for each load resistor was downloaded to a computer and analyzed with Excel to calculate the energy of the pulse. Figure 5 shows a plot of the raw and analyzed data for a load resistance of $250 \Omega$ taken from Excel.

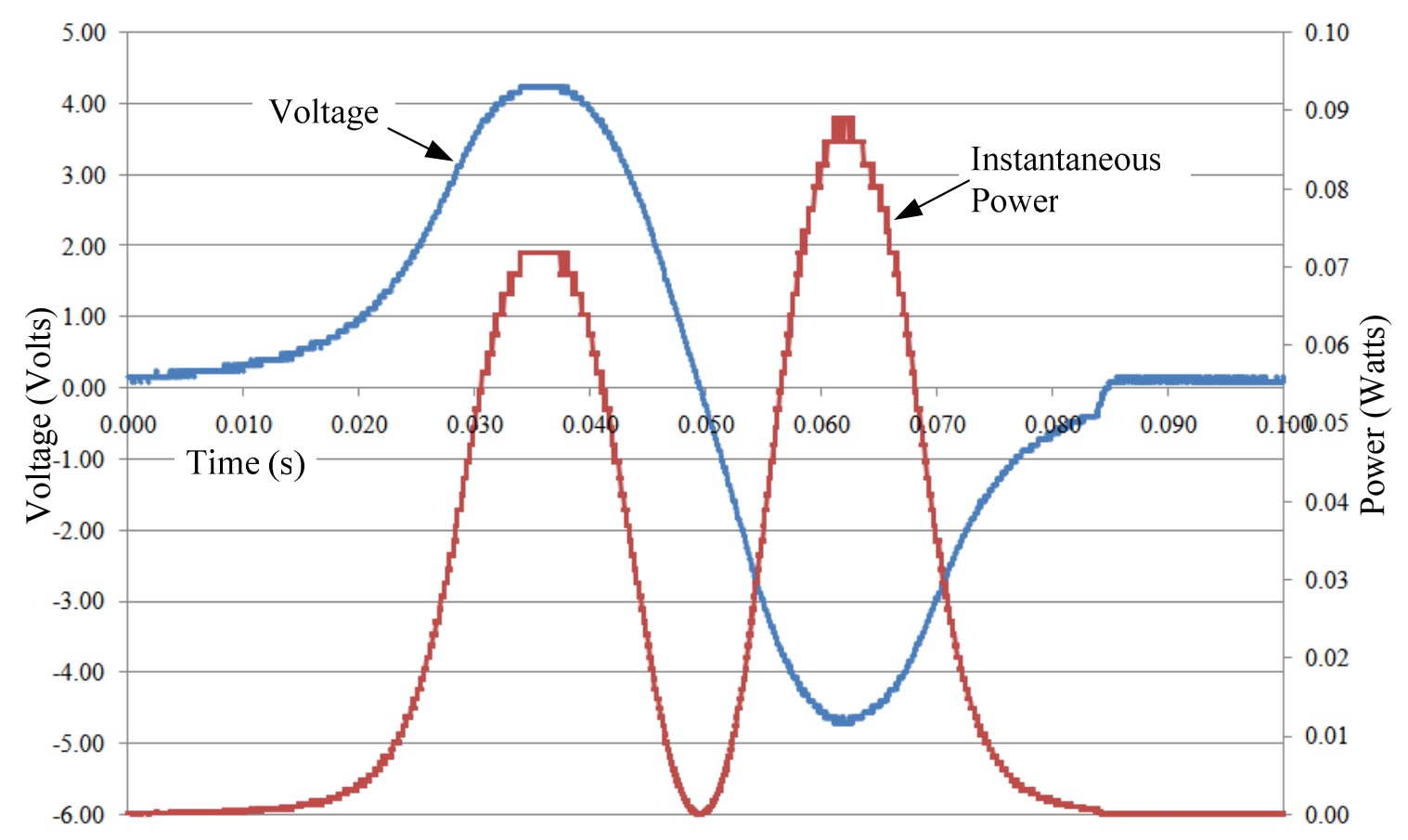

Figure 5. Downloaded and analyzed data for $\mathrm{R}=250 \Omega$.

The instantaneous power curve shown in Figure 5 was discretely integrated in Excel to determine the coil electrical output energy for each value of load resistor tested. The maximum energy output occurred for a load resistance of $250 \Omega$. The corresponding energy was $2.35 \mathrm{~mJ}$. For this load resistance, the time between the voltage waveform maximum and minimum was measured to be $10.48 \mathrm{~ms}$. The average magnet velocity in the coil was therefore about $2.48 \mathrm{~m} / \mathrm{s}$. The resulting kinetic energy of the falling magnet was $67.7 \mathrm{~mJ}$. Finally, the magnet-coil generator efficiency was calculated to be about $3.5 \%$.

Hand-crank Flashlight

The hand-crank flashlight utilized a small permanent magnet DC motor as an electrical generator. The crank was connected to the DC motor shaft through an extensive plastic gear train apparently to increase the rotational speed experienced by the motor during normal human cranking operation. To determine the efficiency of the system, a method of measuring the system input energy at the crank shaft had to be conceived.

The student team came up with the idea to connect a handheld electric drill to the point where the hand-crank attaches to its shaft. By measuring the electrical input power to the drill with no 
mechanical load and then connected to the loaded generator while keeping the rotational speed constant, they hoped to be able to determine the system efficiency. Figure 6 shows a photograph of the system test setup.

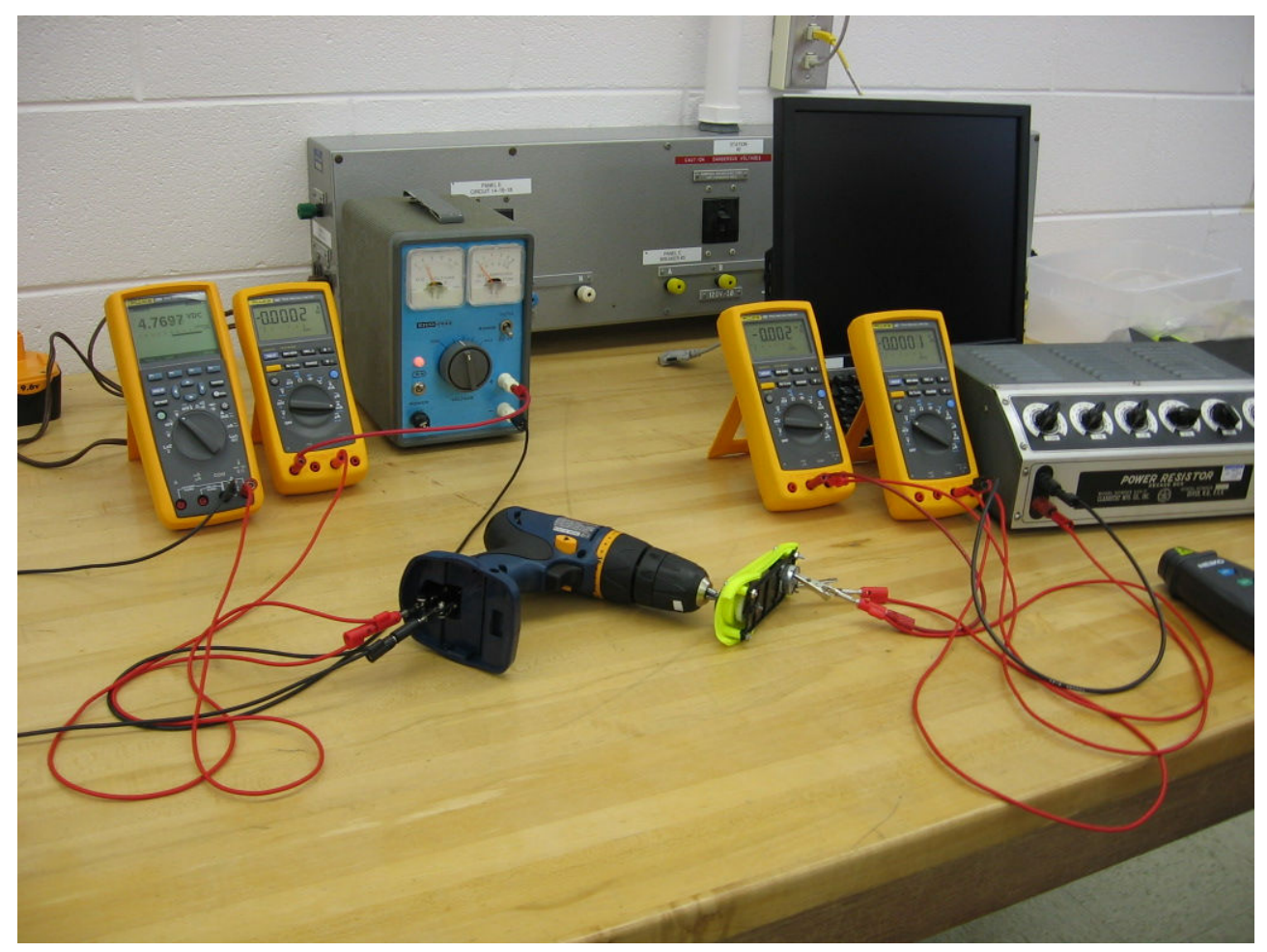

Figure 6. Hand-crank flashlight generator efficiency test setup.

The bench power supply was used in place of the battery to power the variable speed drill to eliminate battery discharging issues. The drill input voltage and current were measured to determine system input power. The DC generator output voltage and current were measured to determine system output power. The generator output was loaded with various load resistor values. The drill speed was measured with an optical tachometer. Table 1 shows the data and results of the hand-crank flashlight efficiency test.

The team needed to know at what shaft speed to perform the testing. Several trials were performed with team members hand-cranking a new flashlight to determine what speeds were comfortable and typical. The team decided upon the speed of $122 \mathrm{rpm}$. All of the data shown in Table 1 was taken with the drill speed set to $122 \pm 2 \mathrm{rpm}$. 


\begin{tabular}{|c|c|c|}
\hline & Drill only & Loaded \\
\hline Input Voltage & $2.78 \mathrm{~V}$ & $2.5 \mathrm{~V}$ \\
\hline Input Current & $1.22 \mathrm{~A}$ & $1.94 \mathrm{~A}$ \\
\hline Output Voltage & $\mathrm{NA}$ & $10.6 \mathrm{~V}$ \\
\hline Output Current & $\mathrm{NA}$ & $36 \mathrm{~mA}$ \\
\hline Input Power & $3.39 \mathrm{~W}$ & $4.85 \mathrm{~W}$ \\
\hline Output Power & 0 & $0.381 \mathrm{~W}$ \\
\hline$\Delta$ Input Power & \multicolumn{2}{|c|}{$1.46 \mathrm{~W}$} \\
\hline$\Delta$ Output Power & \multicolumn{2}{|c|}{0.381} \\
\hline Efficiency & \multicolumn{2}{|c}{$26 \%$} \\
\hline
\end{tabular}

Table 1. Hand-crank flashlight efficiency measurement data

Flywheel - DC generator investigation

The hand-squeezed flashlight uses a custom permanent magnet alternator design. The alternator coil is stationary while a permanent magnet disc rotates above it thus producing an alternating output voltage. Figure 7 shows photographs of a disassembled hand-squeezed flashlight unit.
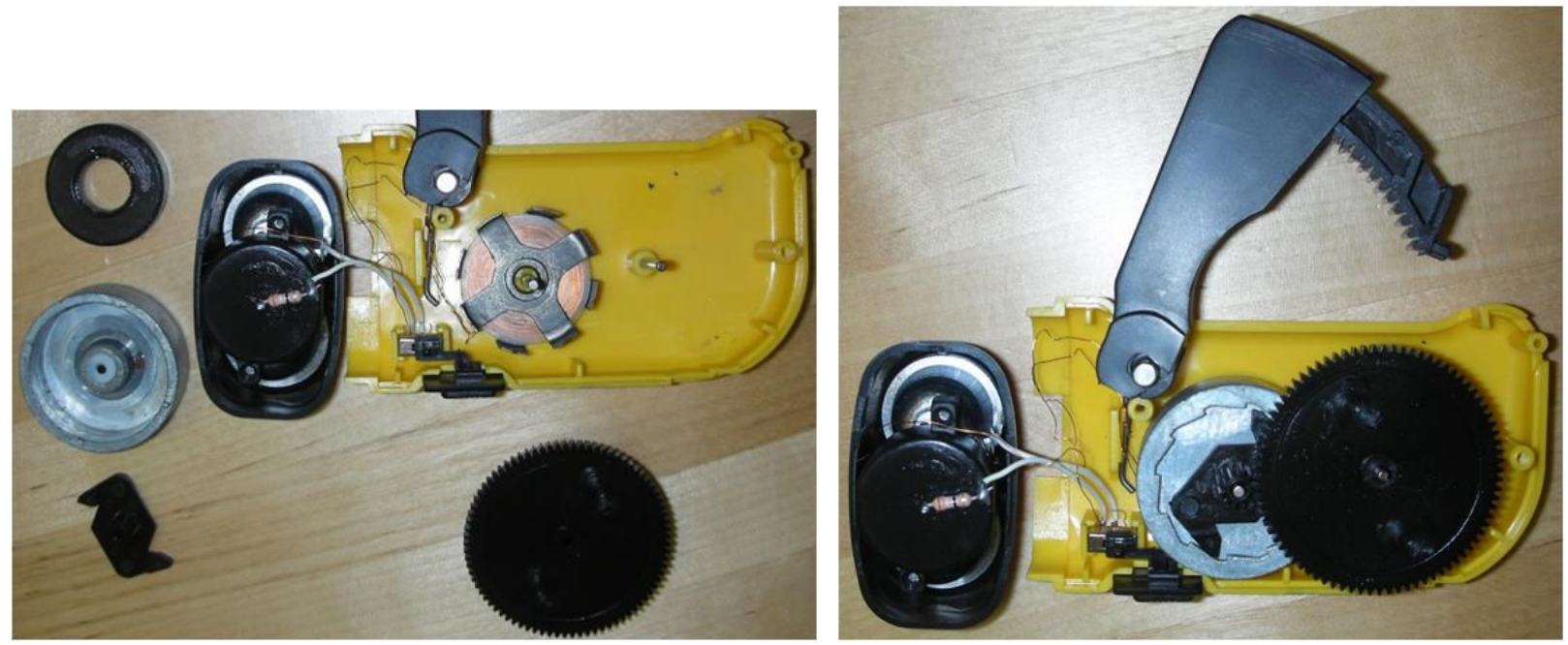

Figure 7. Disassembled hand-squeezed flashlight 
The hand-squeezed lever engages a large gear which in turn drives a ratcheting device which engages the flywheel and disc magnet assembly. The action of squeezing the lever is thereby transferred into spinning the flywheel-magnet of the alternator. The flywheel-magnet assembly from two manufacturers (red and yellow) were weighed and measured to determine their moment of inertia. Figure 8 and Table 2 show the data and analysis of the flywheel-magnet components.

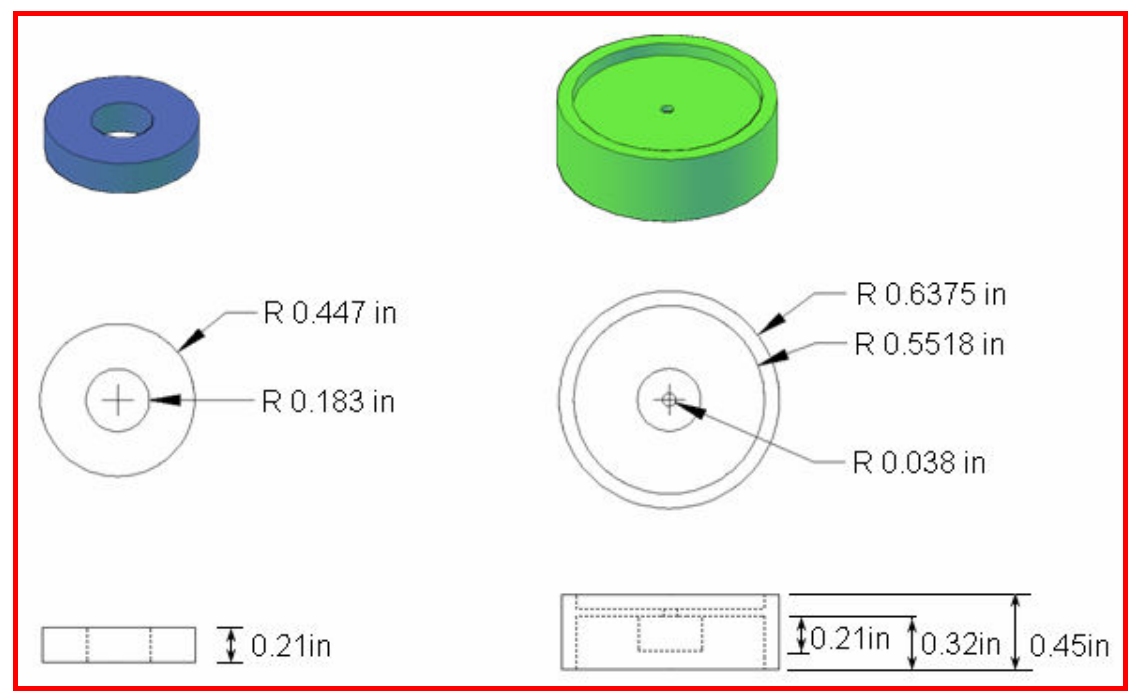

Figure 8. Assembly drawings for disc magnet and flywheel components

\begin{tabular}{|c|c|c|c|}
\hline & & Red & Yellow \\
\hline \multirow{2}{*}{$\begin{array}{c}\text { Mass } \\
(\mathrm{g})\end{array}$} & Magnet & 8 & 9 \\
\hline & Flywheel & 3 & 23 \\
\hline \multirow{3}{*}{$\begin{array}{l}\text { Volume } \\
\left(\mathrm{cm}^{3}\right)\end{array}$} & Magnet & 1.885 & 1.901 \\
\hline & Part A & 2.032 & 2.655 \\
\hline & Part B & .672 & .574 \\
\hline \multirow{3}{*}{$\begin{array}{c}\text { Moment of } \\
\text { Inertia } \\
\left(\mathrm{kg} \cdot \mathrm{m}^{2}\right)\end{array}$} & Magnet & $7.21 \mathrm{E}-7$ & 7.46 E-7 \\
\hline & Part A & $4.97 \mathrm{E}-7$ & $4.26 \mathrm{E}-6$ \\
\hline & Part B & $7.4 \mathrm{E}-8$ & $3.8 \mathrm{E}-7$ \\
\hline
\end{tabular}

Table 2. Data and results for disc magnet and flywheel parts.

The student then constructed a custom flywheel and generator system using a small permanent magnet DC motor as the generator. The results of an earlier energy harvesting investigation required that the flywheel be sized to store about 26 Joules of energy. ${ }^{2}$ The flywheel was coupled to the generator via a pulley and belt system such that the motor would run near its 
optimum speed of 2200rpm when the flywheel was spinning to produce about $26 \mathrm{~J}$ of stored energy per the equation ${ }^{3}$ :

$$
W_{m}=\frac{1}{2} l \omega^{2}
$$

Figure 9 shows a photograph of the student-designed system.

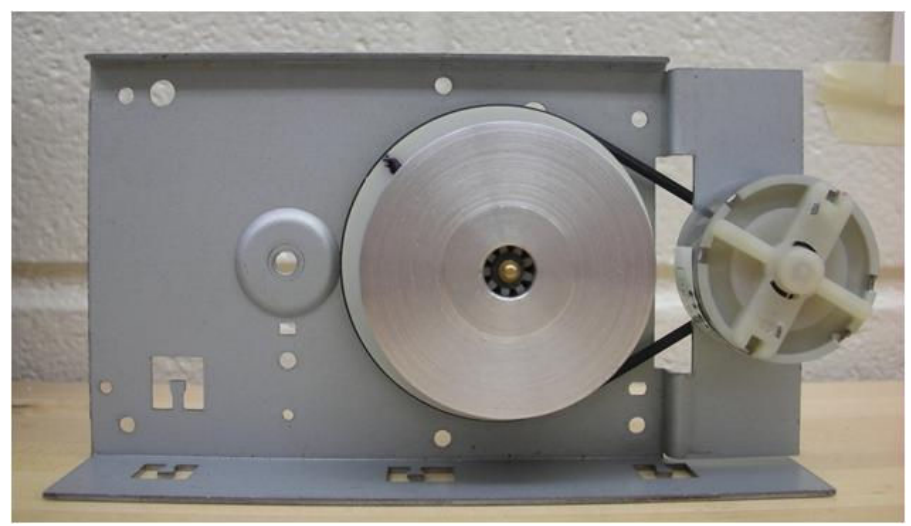

Figure 9. Student-designed and built flywheel and generator assembly

The flywheel-generator system was tested in the circuit shown in Figure 10. The system was spun up to speed (212rpm flywheel) using an external power supply, E. The single-pole, doublethrow (SPDT) switch was then thrown to position 2. The motor then became a generator connected to the capacitor via the diode, D1. By measuring the change in capacitor voltage, the energy could be calculated. The energy on the capacitor was a portion of the energy originally stored in the spinning flywheel.

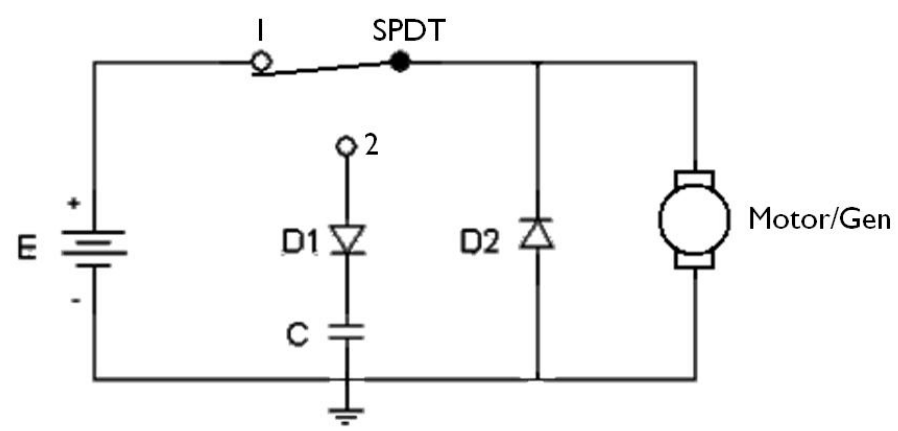

Figure 10. Custom flywheel-generator test setup schematic.

Figure 11 shows the measured waveforms from the test setup of Figure 10. Shown are the capacitor voltage and DC generator output voltage waveforms. A capacitor value of $4700 \mu \mathrm{F}$ was used for this test. The capacitor voltage reaches a maximum of about $1.7 \mathrm{~V}$ which would indicate 
a stored energy of only $6.8 \mathrm{~mJ}$. Obviously, this configuration of generator output voltage, generator shaft speed, and capacitor value is far from optimal for recovering the flywheel energy. However, the concept has been demonstrated and the student is continuing to work in this area.

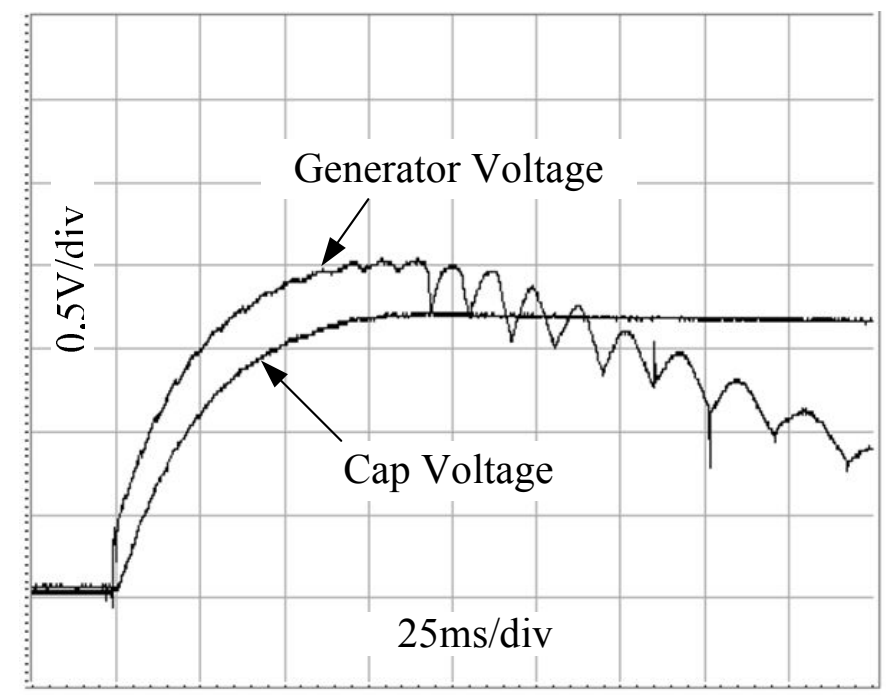

Figure 11. Generator output and capacitor charging voltage waveforms

\section{Conclusions}

The purpose of the activities presented here was to engage undergraduate engineering technology students with investigations into topics that are of current importance. The students were given the opportunity to try out ideas that may typically require additional knowledge or experience but can be explored to provide a meaningful learning experience. Several key conceptual tangents were taken advantage of during these exercises.

The difficulties encountered when trying to weigh the magnet provided a significant teaching (and learning) moment. The use of the digital oscilloscope together with Excel analysis demonstrated that engineers really do use some of that calculus they are required to take. The data taken in the lab may hold much more information than originally expected as was found with the shaker flashlight voltage waveform. During the testing, the students were required to think in terms of energy and not just circuit or mechanics equations.

By thinking about energy, the students began to make some key observations about energy transfer. There was no measureable slowing down of the dropped magnet in the shaker flashlight indicating that little energy was being taken from it. Conversely, when the load resistance applied to the generator output of the hand-crank flashlight was decreased, it took a great deal more energy from the drill to keep it turning at the same speed. At this point, the students were introduced to the concept of dynamic braking which is a very useful technique in electric 
vehicles. Also, the flywheel of the custom system kept going even after the capacitor had reached is maximum charged value indicating that a good amount of energy remained in the spinning mass that was not captured.

\section{Acknowledgements}

The authors would like to thank the first-year student team of John Turner, Erik Stocker, Joshua Zatratz, and Pablo Gallo for their ideas, and ingenuity in the human-powered flashlight investigation.

\section{Bibliography}

1. Yildiz, F. and Zora, A., "Using one dimensional software tools in low-power ambient energy harvesting and generation simulations," Proceedings of the American Society for Engineering Education Annual Conference and Exposition, 2009

2. Litwhiler, D. H. and Gavigan, T. H., "Energy Harvesting: Measurement and Analysis of Swing Doors," Journal of Engineering Technology, Vol. 25, No. 2, Fall 2008, pp 26-31.

3. Haladay, D. and Resnick, R., Fundamentals of Physics, $2^{\text {nd }}$ edition, Wiley, 1981, pp 191-192. 